\title{
Clinical features of late-onset circulatory dysfunction in premature infants
}

This article was published in the following Dove Press journal:

Research and Reports in Neonatology

29 July 2014

Number of times this article has been viewed

\section{Norihisa Koyama' \\ Masanori Kouwaki' \\ Taihei Tanaka ${ }^{2}$ \\ Shigeru Ohki ${ }^{3}$ \\ Kazuhiro Iwase ${ }^{4}$ \\ Shunichi Terasawa ${ }^{5}$ \\ Masanao Miyaji ${ }^{6}$ \\ Toshimitsu Iwaki ${ }^{7}$ \\ Minoru Kokubo ${ }^{8}$ \\ Satoru Kobayashi ${ }^{9}$ \\ Haruo Mizuno ${ }^{10}$ \\ Shinji Fujimoto 10 \\ Hajime Togari ${ }^{10}$}

'Department of Pediatrics, Toyohashi Municipal Hospital, Toyohashi, ${ }^{2}$ Department of Pediatrics, Nagoya Daini Red Cross Hospital, Nagoya, ${ }^{3}$ Department of Pediatrics, Seirei Hamamatsu General Hospital, Hamamatsu, ${ }^{4}$ Department of Pediatrics, Nagoya City West Medical

Center, Nagoya, ${ }^{5}$ Department of Pediatrics, Ichinomiya Municipal Hospital, Ichinomiya, ${ }^{6}$ Department of Pediatrics, Shizuoka Saiseikai General Hospital, Shizuoka, ${ }^{7}$ Department of Pediatrics, Gifu Prefectural Tajimi Hospital, Tajimi, ${ }^{8}$ Department of Pediatrics, Kainan Hospital Aichi Prefectural Welfare Federation of Agricultural Cooperatives, Yatomi, ${ }^{9}$ Department of Pediatrics, Seirei Mikatabara General Hospital, Hamamatsu, ${ }^{10}$ Department of Pediatrics, Neonatology and Congenital Disorders, Nagoya City University Graduate School of Medical Sciences, Nagoya, Japan

Correspondence: Norihisa Koyama Department of Pediatrics, Toyohashi Municipal Hospital, 50, Hachiken-nishi, Aotake, Toyohashi, Aichi 44I-8570, Japan Tel +8I 5323361 II

Fax +8I 532336177

Email n.koyama@nifty.com
Background: Sudden unpredictable hypotension during the post-transitional period, termed late-onset circulatory dysfunction (LCD) of premature infants, has been reported in low birthweight infants who overcame major problems during the early neonatal period. We investigated the clinical features of LCD and factors associated with the occurrence of LCD.

Methods: A multicenter retrospective case-control study. The clinical records of 1,004 children born at less than 32 weeks of gestation were reviewed. Patients with LCD were compared with age-matched non-LCD controls.

Results: Of the 1,004 infants, 73 (7.3\%) were diagnosed with LCD, with the incidence differing significantly among institutions $(P<0.0001)$. The median age of diagnosis was 16 days of age (range: 4-50 days) and 29 weeks of postmenstrual age (range: 25-35 weeks). The incidence of LCD was inversely correlated with gestational age at birth, except at 22 and 23 weeks. Compared with the control infants, the LCD infants had significantly higher incidences of birth by cesarean section $(61 / 73$ versus 48/73, $P<0.05$ ); hyponatremia (sodium $<130 \mathrm{mEq} / \mathrm{L}$ ) at the time of diagnosis (24/66 versus 3/39, $P<0.01$ ); deterioration of respiratory status within 24 hours before diagnosis (36/73 versus 6/73, $P<0.0001)$; and periventricular leukomalacia (14/73 versus $4 / 73, P<0.05)$. Corticosteroids were effective in 52 infants who were unresponsive to volume expansion or inotropic agents. None of these infants died of LCD.

Conclusion: LCD is common but worthy of attention due to its association with periventricular leukomalacia. A review of institutional differences in treatment policies may contribute to the prevention of LCD.

Keywords: late-onset circulatory dysfunction of premature infants, low birth-weight infant, shock, adrenocortical insufficiency, periventricular leukomalacia

\section{Introduction}

Systemic hypotension frequently occurs in very low birth-weight infants during the early neonatal period. ${ }^{1-4}$ During the post-transitional period, however, some of these infants experience sudden refractory hypotension that is usually resistant to volume expansion and inotrope treatment, a condition called late-onset circulatory dysfunction (LCD) of premature infants..$^{5-8}$ The onset of LCD is unpredictable, and it often occurs in the absence of obvious causes (such as hemorrhaging, sepsis, and symptomatic patent ductus arteriosus) in infants who overcame major respiratory and circulatory problems during the early neonatal period.

The number of infants with LCD has been increasing in Japan. ${ }^{5-8}$ It was reported that the prevention of this disease could lead to improved neurological prognosis of those infants, ${ }^{8}$ but the clinical features and pathogenesis of this condition have 
not yet been determined. So we performed a multi-center retrospective case-control study to investigate the clinical features of LCD and factors associated with its occurrence, and looked for clues to prevent this disease.

\section{Methods Study subjects}

We reviewed the clinical records of all infants who were born at less than 32 weeks of gestation and were admitted to one of nine neonatal intensive care units in the Chubu area of Japan between January 1, 2000, and December 31, 2004. Infants who suffered early neonatal death, major anomalies, chromosomal abnormalities, or multiplets, except for dichorionic diamniotic twins, were excluded.

\section{Study design}

Each LCD infant was compared with gestational age matched ( $<1$ week difference) non-LCD controls admitted to the same institution just after the LCD infant. Clinical data at and before the time of LCD diagnosis were compared with that of the control patient at the same age. Mean heart rate and blood glucose concentration measured on the day before LCD diagnosis, were compared with that of the control patient at the same day of age.

\section{Definitions}

LCD was defined as the sudden development, during the post-transitional period, of hypotension (20\% decrease in systolic or mean blood pressure) and/or oliguria $(50 \%$ decrease in urine volume or less than $1 \mathrm{~mL} / \mathrm{kg} / \mathrm{hr}$ of urine over 8 hours, or no urination for over 4 hours) after a period of stable respiration and circulation, without an obvious cause such as hemorrhaging, sepsis, or symptomatic patent ductus arteriosus. Symptomatic patent ductus arteriosus as a cause of hypotension was excluded by ultrasonography in all LCD patients. Each of these infants was assessed for C-reactive protein concentration and blood culture results, and only those negative for all these markers were confirmed as having LCD. Intraventricular hemorrhage was diagnosed by cranial ultrasonography. ${ }^{9}$ Periventricular leukomalacia (PVL) was diagnosed by the presence of periventricular cysts $(>3 \mathrm{~mm})$ on cranial ultrasonography performed at $0,1,2$, and 7 days of age, and once per week thereafter during hospitalization. In some infants, PVL was diagnosed by cranial computed tomography or magnetic resonance imaging after discharge from the hospital. In these infants, PVL was diagnosed by the presence of ventricular dilatation and/or reductions in periventricular white matter. Chorioamnionitis was defined as infection/inflammation of the membranes histologically diagnosed by pathologists at each hospital. Diagnoses of respiratory distress syndrome were based on clinical and chest radiographic findings.

\section{Ethical approval}

This study was approved by the ethics committee of Toyohashi Municipal Hospital, which waived the requirement for informed consent due to the retrospective nature of this study.

\section{Statistical analysis}

All statistical analyses were performed using JMP (Release 5.1.2; SAS Institute Inc., Cary, NC, USA). Differences between medians were analyzed using Wilcoxon rank-sum tests, and differences between means were analyzed using unpaired Student's $t$-tests. Categorical data were analyzed using the $\chi^{2}$ test or Fisher's exact test. Variables with $P<0.2$ by bivariate analysis were included in multivariate analysis using logistic regression. A $P$-value $<0.05$ was defined as statistically significant.

\section{Results Incidence}

Of the 1,236 infants born at less than 32 weeks of gestation, 232 were excluded, 40 due to early neonatal death, 15 for major anomalies, six for chromosomal abnormalities, 168 for being multiplets (not including dichorionic diamniotic twins), and three for loss of medical records. Of the remaining 1,004 infants, 73 (7.3\%) were diagnosed with LCD, including 38/538 (7.1\%) males and 35/466 (7.5\%) females. In infants born at less than 28 weeks of gestation, the incidence was $14.8 \%$. Incidence was inversely correlated with gestational age at birth, except at 22 and 23 weeks, and was highest at 24 weeks $(14 / 58 ; 24.1 \%)$ (Figure 1). From 2000 to 2004 , LCD tended to increase, being 6/166 (3.6\%) in $2000,15 / 208(7.2 \%)$ in $2001,10 / 196(4.9 \%)$ in $2002,17 / 211$ $(8.1 \%)$ in 2003 , and $25 / 213(11.7 \%)$ in 2004 . The incidence of LCD differed significantly among the nine institutions $(P<0.0001$; Table 1).

\section{Clinical features}

Median age at the time of LCD diagnosis was 16 days of age (total range: 5-50 days) and 29 weeks 5 days of postmenstrual age (total range: 25 weeks 0 days to 35 weeks 2 days). We compared 73 LCD patients with 73 gestational age-matched controls. Table 2 shows the clinical characteristics of the two groups. There were no between-group differences in 


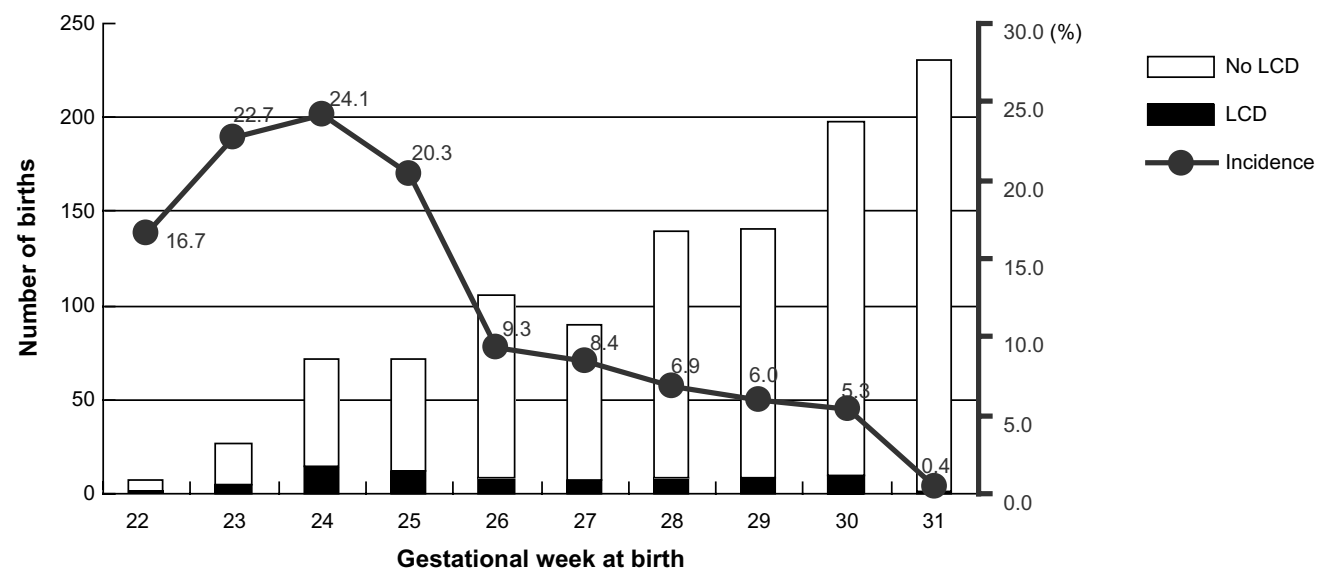

Figure I Relationship between incidence of LCD and gestational age at birth.

Note: The incidence of LCD was inversely correlated with gestational age at birth, except for at 22 and 23 weeks, and was highest at 24 weeks (14/58, $24.1 \%$ ).

birth weight. Birth by cesarean section was statistically significantly more common in the LCD than in the control group (61/73 versus [vs] 48/73, $P=0.013)$. The day before LCD diagnosis, mean \pm standard deviation heart rate was higher in the LCD than in the control group $(158.7 \pm 11.5$ vs $151.9 \pm 10.3, P=0.0002)$. Moreover, the incidences of hyponatremia $(\mathrm{Na}<130 \mathrm{mEq} / \mathrm{L}, 24 / 66$ vs $3 / 39, P=0.001)$ and hyperkalemia $(\mathrm{K}>5.5 \mathrm{mEq} / \mathrm{L}, 13 / 65$ vs $2 / 39, P=0.037)$ were higher in the LCD group, as was the incidence of respiratory status deterioration within 24 hours before the diagnosis of LCD (36/73 vs 6/73, $P<0.0001)$. At the time of LCD diagnosis, a higher percentage of infants in the LCD group required respiratory support ( $60 / 73$ vs $44 / 73, P=0.0034)$, including continuous nasal positive airway pressure (24/73 vs $17 / 73, P=0.2)$, intermittent mandatory ventilation ( $16 / 73 \mathrm{vs}$ 20/73, $P=0.44$ ), and/or high frequency oscillatory ventilation (20/73 vs $7 / 73, P=0.0056$ ). Seven LCD infants, however, showed no signs of respiratory insufficiency and breathed spontaneously without oxygen supplementation. There were

Table I Incidence of LCD according to institution

\begin{tabular}{llll}
\hline Institution & $\begin{array}{l}\text { Number } \\
\text { of infants }\end{array}$ & $\begin{array}{l}\text { Infants } \\
\text { with LCD }\end{array}$ & $\begin{array}{l}\text { Incidence } \\
\text { (\%) }\end{array}$ \\
\hline A & 203 & 36 & 17.7 \\
B & 208 & 16 & 7.7 \\
C & 138 & 7 & 5.1 \\
D & 127 & 1 & 0.8 \\
E & 85 & 2 & 2.4 \\
F & 109 & 0 & 0.0 \\
G & 48 & 10 & 20.8 \\
H & 29 & 1 & 3.4 \\
I & 57 & 0 & 0.0 \\
Total & 1,004 & 73 & 7.3 \\
\hline
\end{tabular}

Notes: The incidence of LCD differed significantly among the 9 institutions $(P<0.0001)$.

Abbreviation: LCD, late-onset circulatory dysfunction of premature infants. no between-group differences in the administration of prenatal steroids to mothers or postnatal steroids to infants during early neonatal period or in steroid inhalation at the time of LCD diagnosis. The frequency of steroid infusion after 7 days of age was statistically significantly higher in the LCD group in comparison with the non-LCD group (7/73 vs $1 / 73, P=0.027$ ). The administration of diuretics $(14 / 73$ vs $5 / 73, P=0.027)$ and theophylline and/or caffeine ( $54 / 73$ vs $45 / 73, P=0.011)$ at the time of diagnosis was statistically significantly more common in the LCD than in the control group.

Multivariate logistic regression analysis (Table 4) showed that deterioration of respiratory status within 24 hours before LCD diagnosis (odds ratio [95\% confidence interval] 11.433 [3.87-40.56]; $P<0.0001$ ), cesarean section (odds ratio [95\% confidence interval], 4.25 [1.30-15.60]; $P=0.021$ ), chorioamnionitis (odds ratio [95\% confidence interval], 2.78 [1.08-7.59]; $P=0.039$ ), and PVL (odds ratio [95\% confidence interval], 4.54 [1.14-21.93]; $P=0.042$ ) were significantly and independently associated with the onset of LCD.

\section{Endocrinologic findings}

In eleven LCD infants, adrenal function was investigated just prior to treatment. Table 3 shows plasma cortisol and adrenocorticotropic hormone concentrations in these infants.

\section{Treatment}

All LCD patients required some treatments. Of the 73 infants with LCD, 66 were treated with volume expansion, 65 were administered inotropic agents, and 52 were administered corticosteroids. Corticosteroids were effective in all 52 patients, including 51 who were unresponsive to volume expansion and/or inotropic agents. The numbers of patients in response to each regimen were as follows: two, 
Table 2 Clinical characteristics of the LCD and control groups

\begin{tabular}{|c|c|c|c|}
\hline Clinical features & LCD $(n=73)$ & Control $(n=73)$ & $P$ \\
\hline \multicolumn{4}{|l|}{ Birth-related factors } \\
\hline Gestational age ${ }^{\#}$ & 26 w $3 d(-24 w 4 d-28 w 6 d)$ & 26 w $5 d(-25 w \mid d-29 w 2 d)$ & 0.43 \\
\hline Birth weight $(g)^{\#}$ & $850(\sim 668.5-1,067)$ & $852(\sim 728-1,100)$ & 0.24 \\
\hline Outborn & $\mathrm{I}$ & 6 & 0.12 \\
\hline C-section & 61 & 48 & 0.013 \\
\hline Male:female & $38: 35$ & $38: 35$ & I \\
\hline Light-for-date & 14 & 12 & 0.67 \\
\hline APGAR score (I minute) $)^{\#}$ & $3(\sim 2-6)$ & $4(\sim 2-7)$ & 0.35 \\
\hline APGAR score (5 minutes) $)^{\#}$ & $6(\sim 4-8)$ & $7(\sim 5-9)$ & 0.09 \\
\hline Chorioamnionitis & $36 / 67$ & $26 / 68$ & 0.07 \\
\hline \multicolumn{4}{|l|}{ Clinical data on the day before LCD diagnosis } \\
\hline Body weight/birth weight ratio & $1.00 \pm 0.19$ & $1.00 \pm 0.18$ & 0.83 \\
\hline Water intake (mL/kg/day) & $119.5 \pm 41.7$ & $|27.4 \pm 6| .7$ & 0.37 \\
\hline Heart rate (beats/min) & $|58.7 \pm 1| .5$ & $151.9 \pm 10.3$ & 0.0002 \\
\hline $\mathrm{Na}<130 \mathrm{mEq} / \mathrm{L}$ & $24 / 66$ & $3 / 39$ & 0.001 \\
\hline $\mathrm{K}>5.5 \mathrm{mEq} / \mathrm{L}$ & $13 / 65$ & $2 / 39$ & 0.037 \\
\hline Blood glucose (mg/dL) & $104.3 \pm 42.3$ & $99.2 \pm 35.4$ & 0.52 \\
\hline \multicolumn{4}{|l|}{ Respiratory status at LCD diagnosis } \\
\hline Spontaneous respiration (room air) & 7 & 12 & 0.22 \\
\hline Spontaneous respiration $\left(\mathrm{O}_{2}\right.$ supplementation $)$ & 6 & 17 & 0.0125 \\
\hline Respiratory support & 60 & 44 & 0.0034 \\
\hline$n-C P A P$ & 24 & 17 & 0.2 \\
\hline IMV & 16 & 20 & 0.44 \\
\hline HFOV & 20 & 7 & 0.0056 \\
\hline Deterioration of respiratory status $<24$ hours before diagnosis & 36 & 6 & $<0.000$ I \\
\hline \multicolumn{4}{|l|}{ Medication } \\
\hline \multicolumn{4}{|l|}{ Perinatal } \\
\hline Prenatal steroid treatment & 27 & 22 & 0.38 \\
\hline Postnatal steroid infusion before LCD diagnosis & 13 & 9 & 0.35 \\
\hline$<$ day 7 & 8 & 8 & 1.00 \\
\hline$\geqq$ day 7 & 7 & 1 & 0.027 \\
\hline Indometacin for symptomatic PDA & 15 & 22 & 0.18 \\
\hline \multicolumn{4}{|l|}{ At LCD diagnosis } \\
\hline Diuretics & 14 & 5 & 0.027 \\
\hline Theophylline and/or caffeine & 54 & 45 & 0.011 \\
\hline Doxapram & 10 & 15 & 0.27 \\
\hline Steroid inhalation & 3 & 2 & 0.65 \\
\hline Oral $\mathrm{Na}$ supplementation & 27 & 27 & 1 \\
\hline \multicolumn{4}{|l|}{ Complications } \\
\hline Respiratory distress syndrome & 56 & 51 & 0.349 \\
\hline Pulmonary hemorrhage & 5 & 2 & 0.25 \\
\hline IVH (grade III and IV) & 8 & 4 & 0.23 \\
\hline $\mathrm{O}_{2}$ requirement $\left(\right.$ days) ${ }^{\#}$ & $64(\sim 45-88.5)$ & $61(\sim 26.5-79.5)$ & 0.13 \\
\hline $\mathrm{O}_{2}$ dependence at 28 days of age & 66 & 54 & 0.009 \\
\hline $\mathrm{O}_{2}$ dependence at 36 weeks of post conceptional age & 36 & 28 & 0.21 \\
\hline PVL & 14 & 4 & 0.012 \\
\hline ROP & 33 & 23 & 0.1 \\
\hline Died & I & I & 1 \\
\hline
\end{tabular}

Notes: Data in the LCD at the time of LCD diagnosis were compared with data in the control group at the same age. ${ }^{\#}$, median (interquartile range).

Abbreviations: C-section, cesarean section; HFOV, high-frequency oscillatory ventilation; HOT, home oxygen therapy; IMV, intermittent mandatory ventilation; $\mathrm{IVH}$, intraventricular hemorrhage; LCD, late-onset circulatory dysfunction of premature infants; n-CPAP, nasal continuous positive airway pressure; PDA, patent ductus arteriosus; PVL, periventricular leukomalacia; ROP, retinopathy of prematurity; w, weeks; d, days.

volume expansion only; four, inotropic agents only; one, sodium loading only; one, corticosteroids only; 14, volume expansion + inotropic agents; four, volume expansion + corticosteroids; one, inotropic agents + corticosteroids; and 46, volume expansion + inotropic agents + corticosteroids.

\section{Prognosis}

The incidence of PVL (14/73 vs 4/73, $P=0.012)$ was statistically significantly higher in the LCD than in the control group (Table 2). Of the 14 LCD infants with PVL, 13 were diagnosed with this condition more than 11 days after LCD 
Table 3 ACTH and cortisol concentrations at LCD diagnosis

\begin{tabular}{|c|c|c|c|c|c|}
\hline LCD & $\begin{array}{l}\text { Age at LCD } \\
\text { diagnosis (days) }\end{array}$ & $\begin{array}{l}\text { Gestational } \\
\text { age at birth }\end{array}$ & $\begin{array}{l}\text { Birth } \\
\text { weight (g) }\end{array}$ & АCTH (pg/mL) & Cortisol $(\mu \mathrm{g} / \mathrm{dL})$ \\
\hline $\mathrm{I}$ & 23 & $24 w 2 d$ & 826 & 11 & 12.8 \\
\hline 2 & 5 & $25 \mathrm{w} 0 \mathrm{~d}$ & 753 & 13.3 & 8.8 \\
\hline 3 & 7 & $25 \mathrm{w} 3 \mathrm{~d}$ & 595 & 20.9 & 4.4 \\
\hline 4 & 6 & $25 w 3 d$ & 733 & 13.5 & 5.9 \\
\hline 5 & 23 & $25 \mathrm{w} 4 \mathrm{~d}$ & 1,028 & 83 & 9.8 \\
\hline 6 & 16 & $26 w 3 d$ & 982 & 36.8 & 6.9 \\
\hline 7 & 37 & $26 w 5 d$ & 850 & 150 & 6.5 \\
\hline 8 & 19 & $29 \mathrm{w} 6 \mathrm{~d}$ & 1,306 & 61 & 7.1 \\
\hline 9 & 15 & $30 \mathrm{w} 0 \mathrm{~d}$ & 904 & nd & 5.4 \\
\hline 10 & 10 & $30 w 5 d$ & $\mathrm{I}, 352$ & 35.6 & 5.1 \\
\hline 11 & 5 & $30 w 6 d$ & 1,130 & 63.3 & 5.6 \\
\hline
\end{tabular}

Abbreviations: ACTH, adrenocorticotropic hormone; LCD, late-onset circulatory dysfunction of premature infants; nd, no data; w, weeks; d, days.

diagnosis (ie, more than 34 days after delivery), with the remaining infant diagnosed on the first day of life. Oxygen dependence was significantly higher in the LCD group at 28 days of age $(66 / 73$ vs $54 / 73, P=0.009)$ but was not at 36 weeks of postmenstrual age. None displayed any clinical symptoms and signs that suggested adrenal insufficiency without steroid administration after the recovery of LCD. One infant in each group died. The infant in the LCD group died of intestinal perforation at age 166 days, and the infant in the control group died of infection at age 27 days. None of the patients in either group died of LCD.

\section{Discussion}

Refractory hypotension resistant to volume expansion and vasopressors has been reported in a significant proportion of very low birth-weight infants during the early neonatal period. ${ }^{4}$ Most of these patients respond to corticosteroids and show an inadequate adrenal response to stress, but this adrenal insufficiency has been reported to disappear by the end of the second week of life. ${ }^{10}$ LCD can be clearly distinguished from hypotension during the early neonatal period by its occurrence during the post-transitional period, by a period of stable respiration and circulation preceding its diagnosis, and by its onset being sudden and lacking any obvious causes. An early report ${ }^{11}$ described six extremely low birth-weight infants who suffered from glucocorticoidresponsive hypotension resistant to volume expansion and vasopressors, findings suggestive of LCD. In Japan, this condition was first recognized in $1996 .{ }^{12}$ Since then, many LCD patients have been reported. $5,6,8$

We found that the incidence of LCD in infants born at less than 32 weeks of gestation was 7.3\%. In Japan, LCD is

Table 4 Multivariate logistic regression analysis of clinical characteristics

\begin{tabular}{|c|c|c|c|}
\hline Clinical features (outcome: LCD) & $\begin{array}{l}\text { Regression } \\
\text { coefficient }\end{array}$ & Odds ratio $(95 \% \mathrm{Cl})$ & $P$ \\
\hline Outborn & 0.280 & $1.749(0.075-18.152)$ & 0.663 \\
\hline C-section & 0.724 & $4.252(\mathrm{I} .30 \mathrm{I}-\mathrm{I} 5.597)$ & 0.021 \\
\hline Gestational age at birth & 0.195 & $5.973(0.305-137.129)$ & 0.247 \\
\hline Apgar score (5 minutes) & 0.087 & $1.191(0.450-3.166)$ & 0.724 \\
\hline Chorioamnionitis & 0.511 & $2.78 \mid(1.075-7.592)$ & 0.039 \\
\hline $\mathrm{O}_{2}$ dependence at 28 days old & -0.170 & $0.711(0.115-4.355)$ & 0.711 \\
\hline Deterioration of respiratory status & 1.218 & II.433 (3.87I-40.559) & $<0.0001$ \\
\hline \multicolumn{4}{|l|}{$<24$ hours before diagnosis } \\
\hline PVL & 0.756 & $4.536(1.137-21.927)$ & 0.042 \\
\hline ROP & 0.047 & $1.098(0.396-3.015)$ & 0.855 \\
\hline $\begin{array}{l}\text { Postnatal steroid infusion before LCD } \\
\text { diagnosis ( } \geqq \text { day } 7 \text { ) }\end{array}$ & 0.631 & $3.529(0.355-83.760)$ & 0.328 \\
\hline Respiratory support & 0.597 & $3.298(0.815-15.278)$ & 0.105 \\
\hline Diuretics at onset & 0.506 & $2.752(0.722-11.949)$ & 0.152 \\
\hline Theophylline or caffeine at onset & 0.258 & $1.675(0.646-4.490)$ & 0.294 \\
\hline
\end{tabular}

Abbreviations: C-section, cesarean section; $\mathrm{Cl}$, confidence interval; $\mathrm{LCD}$, late-onset circulatory dysfunction of premature infants; PVL, periventricular leukomalacia; ROP, retinopathy of prematurity. 
common, and its incidence has recently increased. In spite of careful physical examination, we could not notice the onset of LCD in the majority of the patients. The oldest age of LCD onset was 35 weeks and 2 days of postmenstrual age. So we recommend that blood pressure and urine volume should be carefully monitored until 35 weeks of postmenstrual age.

The pathogenesis of LCD still remains unclear. Prematurity was found to affect the LCD onset. The incidence of LCD was inversely correlated with gestational age at birth, except for infants born at 22 and 23 weeks of gestation, in that the incidence of LCD in these infants was lower than that for infants born at 24 weeks of gestation. This may be related to the small numbers of patients born at 22 and 23 weeks ( 6 and 22, respectively) and their high mortality rates $(63.6 \%$ and $35.7 \%$, respectively). Improvement of the mortality of premature infants may be associated with a rise in the recent incidence of LCD.

It is interesting that high frequency oscillatory ventilation was associated with LCD. The reduction in venous return with this type of ventilation might contribute to LCD. Ultrasonography denied symptomatic patent ductus arteriosus in all the LCD patients at diagnosis and none was reported to show poor left ventricle motion. Thus, the high heart rate in the LCD group is suggestive of intravascular hypovolemia. But generalized dehydration does not seem to be a cause of LCD, as the ratio of body weight at diagnosis to birth weight did not differ between the LCD and control groups (Table 2). A previous report showed significant high body weight increase at diagnosis. ${ }^{8}$ These findings suggest fluid shifts from the vessels to third spaces. In addition, diuretics, theophylline, and caffeine can contribute to intravascular hypovolemia. ${ }^{13,14}$

Cesarean section and chorioamnionitis were significantly associated with the onset of LCD, suggesting that some prenatal factors contribute to the pathogenesis of LCD. We reviewed the main reasons for cesarean section but could not find any differences between the LCD and non-LCD group.

LCD is responsive to corticosteroids, and some clinical features of LCD, including hypotension, hyponatremia, and hyperkalemia, resemble those of adrenocortical insufficiency. However, administration of hypotonic solution may induce hyponatremia, and renal failure induced by hypotension could result in hyperkalemia. The accurate evaluation of the adrenal function is necessary to conclude that LCD is adrenal insufficiency. The median plasma cortisol concentration in eleven LCD patients just prior to treatment (Table 3) was $6.5 \mu \mathrm{g} / \mathrm{dL}$ (interquartile range: $5.4-8.8 \mu \mathrm{g} / \mathrm{dL}$ ), indicating a lack of stress despite hypotension. ${ }^{19}$ It is very difficult to interpret these cortisol concentrations without knowing the degree of stress that these infants were experiencing at that time. We are sorry that adrenal function was not investigated in most of the patients because of the nature of the retrospective study. Infants who have received steroids should be carefully examined, for some of them might develop adrenal insufficiency secondary to the exogenous steroid. Of the 73 LCD patients, 18 were administered steroids during the postnatal period before LCD diagnosis. We could classify postnatal steroids treatment into two categories. The first category was the administration for hypotension during the early neonatal period ( $<$ day 7 ), and the other one was the infusion for respiratory distress thereafter ( $\geq$ day 7 ). The frequency of steroid administration during the early neonatal period was not different between the LCD and non-LCD groups (8/73 vs 8/73). On the other hand, the frequency of steroid infusion after 7 days of age was significantly higher in the LCD group (7/73 vs $1 / 73$ : $P=0.027)$. There is a possibility that the adrenal cortex suppression caused by steroid administration contributes to the onset of LCD in those patients. However, most of the LCD patients $(66 / 73)$ developed the disease without steroid infusion after 7 days old. We are convinced that some factors other than postnatal steroid infusion affect the onset of LCD. The total concentrations of cortisol precursors were reported to be statistically significantly higher in those patients than in age matched controls, ${ }^{15}$ suggesting that this circulatory dysfunction is caused by a limited ability to synthesize sufficient amounts of cortisol relative to the degree of clinical stress. In contrast, the hypothalamic-adrenal axis was found to be intact in one patient (patient E), ${ }^{11}$ suggesting that factors other than adrenal insufficiency contribute to the development of LCD. We should be careful about concluding that LCD is adrenal insufficiency. Further investigations of adrenal function, including the response of the hypothalamic-pituitary-adrenal axis to stress, are necessary to clarify the pathogenesis of LCD.

Multivariate logistic regression analysis revealed that PVL was statistically significantly associated with LCD. PVL associated with LCD was characterized by late-onset. The onset of cystic lesions in the PVL infants of the LCD group occurred in all but one patient more than 34 days after delivery, later than reported previously. ${ }^{16,17}$ Stratification of patients with PVL into those with early-onset (at $\leq 28$ days of age) and late-onset (at $>28$ days of age) PVL showed that LCD was significantly and independently associated with late-onset PVL. ${ }^{7}$ In most infants with LCD, systemic hypotension continued for more than several hours. We speculate that systemic hypotension for such a long time may adversely affect brain perfusion and contribute to the development of 
PVL. Indeed, of the 14 infants with PVL in the LCD group, 13 were diagnosed more than 11 days after LCD diagnosis. However, clinical relevance of this association is limited. The age of PVL diagnosis greatly varied among the patients. Thus various other factors during the period before PVL diagnosis may be responsible for the development of PVL. Intrauterine infection-inflammation and cytokine release are also thought to contribute to PVL. ${ }^{16,18}$ The incidence of chorioamnionitis was similar in LCD infants with (5/14) and without (31/53) PVL, suggesting that intrauterine infection-inflammation did not contribute to PVL in these LCD infants.

Our report is the first multi-center analysis of LCD and revealed that the incidence of LCD varied widely among institutions, from $0 \%$ to $20.8 \%$. The difference of the patient's prematurity among participating centers may influence the incidence of LCD. So we investigated the correlation of LCD incidence and the mean gestational age of study infants in each institution, but no correlation was found. Although we used the same definition for LCD through all our institutions, the ascertainment bias due to the differences in monitoring by institutions and by years may affect the incidence of LCD. Institutional differences in treatment policies, including fluid and electrolyte administration, indications for diuretics, ventilator settings, and temperature control may also influence the LCD onset. Unfortunately we could not obtain enough data for statistical analyses of these issues because of the nature of the retrospective case-control study. A review of the differences in institutional treatment policies, in larger-scale prospective trials, may identify strategies to prevent LCD.

\section{Disclosure}

The authors report no conflicts of interest in this work.

\section{References}

1. Gill AB, Weindling AM. Echocardiographic assessment of cardiac function in shocked very low birthweight infants. Arch Dis Child. 1993; 68(1 Spec No):17-21.

2. Pladys P, Wodey E, Bétrémieux P, Beuchée A, Ecoffey C. Effects of volume expansion on cardiac output in the preterm infant. Acta Paediatr. 1997;86(11):1241-1245.

3. Seri I, Evans J. Controversies in the diagnosis and management of hypotension in the newborn infant. Curr Opin Pediatr. 2001;13(2): $116-123$.
4. Ng PC, Lam CW, Fok TF, et al. Refractory hypotension in preterm infants with adrenocortical insufficiency. Arch Dis Child Fetal Neonatal Ed. 2001;84(2):F122-F124.

5. Iijima S, Ohzeki T. A case report of an extremely low birthweight infant with circulatory collapse accompanied by cerebral infarction after the acute period. Am J Perinatol. 2005;22(4):205-209.

6. Kobayashi S, Fujimoto S, Fukuda S, et al. Periventricular leukomalacia with late-onset circulatory dysfunction of premature infants: correlation with severity of magnetic resonance imaging findings and neurological outcomes. Tohoku J Exp Med. 2006;210(4):333-339.

7. Kobayashi S, Fujimoto S, Koyama N, et al. Late-onset circulatory dysfunction of premature infants and late-onset periventricular leukomalacia. Pediatr Int. 2008;50(2):225-231.

8. Nakanishi H, Yamanaka S, Koriyama T, et al. Clinical characterization and long-term prognosis of neurological development in preterm infants with late-onset circulatory collapse. J Perinatol. 2010;30(11): 751-756.

9. Papile LA, Burstein J, Burstein R, Koffler H. Incidence and evolution of subependymal and intraventricular hemorrhage: a study of infants with birth weights less than 1,500 gm. J Pediatr. 1978;92(4):529-534.

10. Ng PC, Lee CH, Lam CW, et al. Transient adrenocortical insufficiency of prematurity and systemic hypotension in very low birthweight infants. Arch Dis Child Fetal Neonatal Ed. 2004;89(2):F119-F126.

11. Helbock HJ, Insoft RM, Conte FA. Glucocorticoid-responsive hypotension in extremely low birth weight newborns. Pediatrics. 1993;92(5): 715-717.

12. Suzuki C, Hidano H, Kitou O. [Four cases of extremely low birth weight infants who developed hypotension due to unknown causes]. J Jpn Soc Premature Newborn Med. 1996;8:333. Japanese.

13. Harkavy KL, Scanlon JW, Jose P. The effects of theophylline on renal function in the premature newborn. Biol Neonate. 1979;35:126-130.

14. Mazkereth R, Laufer J, Jordan S, Pomerance JJ, Boichis H, Reichman H. Effects of theophylline on renal function in premature infants. Am J Perinatol. 1997;14(1):45-49.

15. Masumoto K, Kusuda S, Aoyagi H, et al. Comparison of serum cortisol concentrations in preterm infants with or without late-onset circulatory collapse due to adrenal insufficiency of prematurity. Pediatr Res. 2008;63(6):686-690.

16. Perlman JM, Risser R, Broyles RS. Bilateral cystic periventricular leukomalacia in the premature infant: associated risk factors. Pediatrics. 1996;97(6 Pt 1):822-827.

17. Maria A, Gupta A, Aggarwal R, Sreenivas V, Paul VK, Deorari AK. Incidence of periventricular leucomalacia among a cohort of very low birth weight neonates ( $<1500$ g). Indian Pediatr. 2006;43(3): 210-216.

18. Leviton A, Paneth N, Reuss ML, et al. Maternal infection, fetal inflammatory response, and brain damage in very low birth weight infants. Developmental Epidemiology Network Investigators. Pediatr Res. 1999;46(5):566-575.

19. $\mathrm{Ng}$ PC, Lee CH, Lam CW, et al. Early pituitary-adrenal response and respiratory outcomes in preterm infants. Arch Dis Child Fetal Neonatal Ed. 2004;89(2):F127-F130.

\section{Publish your work in this journal}

Research and Reports in Neonatology is an international, peer-reviewed, open access journal publishing original research, reports, editorials, reviews and commentaries on neonatal health. The manuscript management system is completely online and includes a very quick and fair

\section{Dovepress}

peer-review system. Visit http://www.dovepress.com/testimonials.php to read real quotes from published authors. 